\title{
LKM-1 Autoantibodies Recognize a Short Linear Sequence in P450IID6, a Cytochrome P-450 Monooxygenase
}

Michael P. Manns, " Keith J. Griffin, ${ }^{\ddagger}$ Kevin F. Sullivan," and Eric F. Johnson

*Department of Medicine I, University of Mainz, D-6500 Mainz, Federal Republic of Germany; and Division of Biochemistry, $\ddagger$ Department of Molecular and Experimental Medicine, and §Department of Molecular Biology,

The Scripps Research Institute, La Jolla, California 92037

\begin{abstract}
LKM-1 autoantibodies, which are associated with autoimmune chronic active hepatitis, recognize P450IID6, a cytochrome P-450 monooxygenase. The reactivities of $26 \mathrm{LKM}-1$ antisera were tested with a panel of deletion mutants of P450IID6 expressed in Escherichia coli. 22 sera recognize a 33-amino acid segment of P450IID6, and 11 of these recognize a shorter segment, DPAQPPRD. PAQPPR is also found in IE175 of herpes simplex virus type 1 (HSV-1). Antibodies for HSV-1 proteins were detected by ELISA in 17 of 20 LKM-1 sera tested. An immobilized, synthetic peptide, DPAQPPRDC, was used to purify LKM-1 antibodies. Affinity purified LKM-1 autoantibodies react on immunoblots with a protein in BHK cells after infection with HSV-1. 11 of 24 LKM-1 sera, including 3 that recognize DPAQPPRD, also exhibit antibodies to the hepatitis $C$ virus (HCV) protein, C100-3. Affinity purified LKM-1 antibodies did not recognize C100-3. However, partial sequence identity was evident between portions of the immunopositive 33-amino acid segment of P450IID6 and other portions of the putative HCV polyprotein. Immune cross-recognition of P450IID6 and HCV or HSV-1 proteins may contribute to the occurrence of LKM-1 autoantibodies. (J. Clin. Invest. 1991. 88:1370-1378.) Key words: autoimmune chronic active hepatitis • epitope mapping $\bullet$ hepatitis $\mathrm{C}$ virus $\bullet$ herpes simplex virus, type $1 \cdot$ immune cross-recognition
\end{abstract}

\section{Introduction}

LKM-1 autoantibodies are found in a subgroup of patients with idiopathic autoimmune chronic hepatitis (1). These antibodies recognize P450IID6, ${ }^{1}$ a cytochrome P-450 monooxygenase, as judged by their recognition of the protein expressed from cDNAs as a fusion protein $(3,4)$ and by the capacity of the antibodies to inhibit reactions catalyzed by P450IID6 (5). P450IID6 is associated with the metabolism of debrisoquine

Address reprint requests to Dr. Johnson, Division of Biochemistry/ BCR-7, The Scripps Research Institute, 10666 N. Torrey Pines Road, La Jolla, CA 92037. 1991.

Received for publication 27 March 1991 and in revised form 11 June

1. Conventions used in this article: The generic term "P450" is used to indicate a cytochrome P-450. Individual forms of $\mathrm{P} 450$ are designated according to a uniform system of nomenclature (2).

J. Clin. Invest.

(C) The American Society for Clinical Investigation, Inc.

0021-9738/91/10/1370/09 \$2.00

Volume 88, October 1991, 1370-1378 and other antihypertensive drugs, and defective alleles of the gene encoding P450IID6 occur frequently leading to deficiencies in the metabolism of these compounds in roughly $5-10 \%$ of Caucasians (6). Competitive binding assays described in earlier studies indicated that LKM-1 antibodies from different patients bound to overlapping epitopes on P450IID6 (7). These antibodies recognize both the native enzyme in microsomes as well as the denatured protein in immunoblots, and the latter suggested that these antibodies might recognize a linear segment of the protein.

The present study was undertaken to determine whether these antibodies recognize a linear segment of P450IID6 and to characterize the location and sequence of the immunoreactive segment. We reasoned that this effort would confirm the uniformity of LKM-1 autoreactivity as well as identify other proteins exhibiting similar amino acid sequences that might also react with these antisera. In addition, the identification of an epitope recognized by these inhibitory antibodies could provide additional information regarding the topology of $\mathrm{P} 450$ proteins. We report here the identification of a short segment of P450IID6 that is recognized by almost all LKM-1 autoantibodies.

\section{Methods}

Patient sera. 26 LKM-1 positive sera from patients with hepatitis B surface antigen-negative chronic active hepatitis were the focus of this study. These sera were classified as LKM-12 ${ }^{2}$ positive because of their reactivity by indirect immunofluorescence on rodent liver and kidney tissue sections as well as by positive immunoblots of human liver microsomes and human recombinant LKM-1 (P450IID6) antigen (3). As controls, we used sera from nine patients with primary biliary cirrhosis which were positive for anti-mitochondrial antibodies and sera from six healthy controls without evidence of liver disease.

Construction of deletion mutants. The HLD8.2 cDNA (3) was inserted into the EcoRI site of pBluescript KS- (Stratagene, Inc., La Jolla, CA). The construct was digested with ClaI, and the overhangs were filled-in using Klenow fragment, in order to place the insert in proper reading frame. Transformants of DH5 $\alpha$ cells (Bethesda Research Laboratories, Gaithersburg, MD) harboring this construct expressed a protein which reacted strongly with an LKM-1 positive serum using the immunoscreening procedure described by Helfman et al. (8). Sequence analysis confirmed that the orientation of the insert was correct and that the reading frame of the insert extended that of $\beta$-galactosidase.

Initial mutants were made by deleting a $3^{\prime}$ segment or an internal portion of the coding sequence using the restriction enzymes shown in the legend to Fig. 1. In other cases, an internal restriction fragment was excised and inserted into pBluescript KS- or SK-. For this purpose,

2. Abbreviations used in this paper: $\mathrm{HCV}$, hepatitis $\mathrm{C}$ virus; $\mathrm{HSV}-1$, herpes simplex virus, type 1 ; LKM-1, liver, kidney microsomal autoantibodies, type 1. 

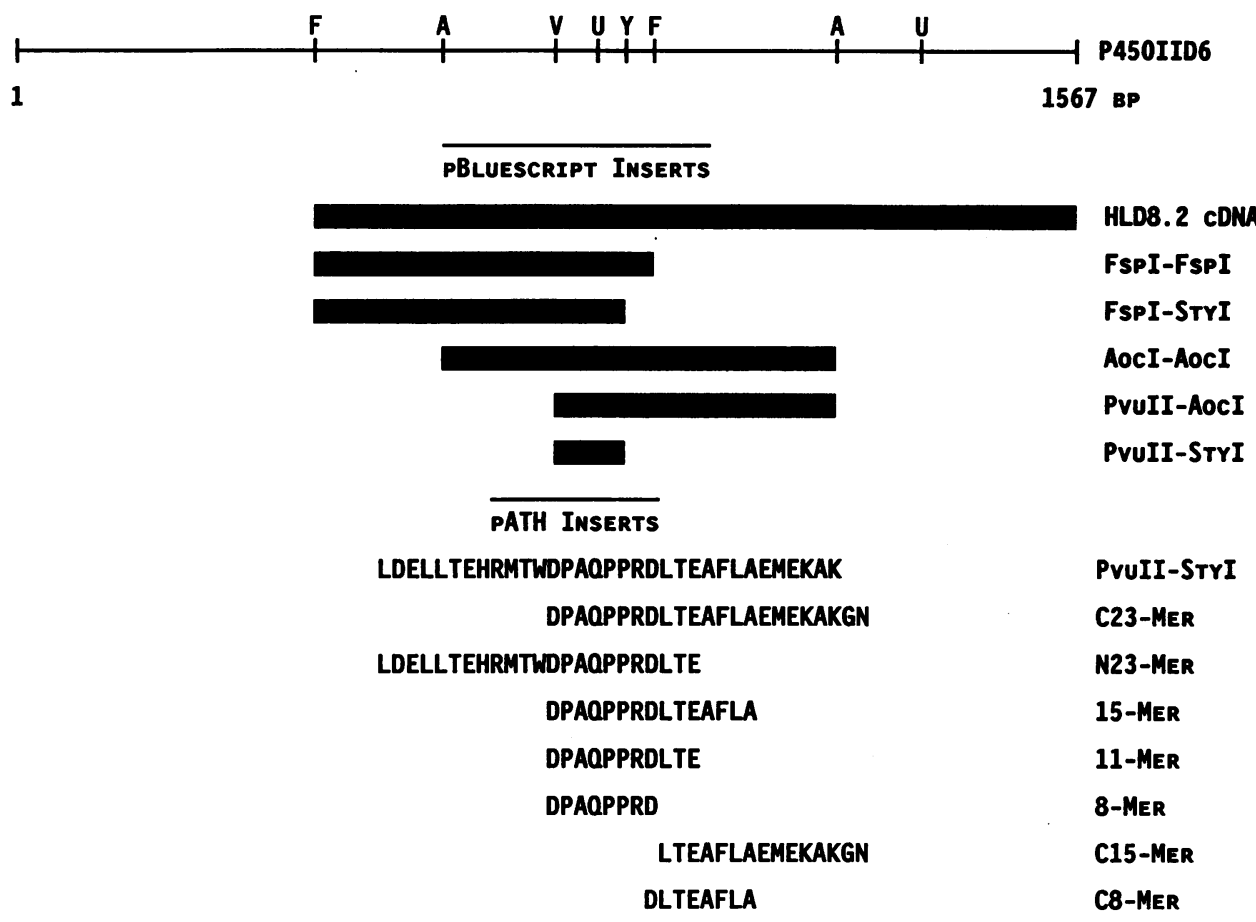

Figure 1. A schematic representation of the deletion analysis used to localize the binding of LKM-1-positive sera. The HLD8.2 cDNA which encodes a protein recognized by LKM-1 sera (3) corresponds to residues 373-1567 of the full-length cDNA characterized by Gonzalez et al. (9). The cDNA was inserted into pBluescript KS- (Stratagene, Inc.) and expressed as a fusion protein with $\beta$-galactosidase. Deletions were made using the indicated restriction sites. Those occurring in the $5^{\prime}$ end of the clone led to in-frame deletions which were confirmed by sequence analysis. The restriction sites are as follows: A, AocI; F, FspI; V, PvuII; U, StuI; Y, StyI. The smallest fragment that encoded a peptide that bound LKM-1 antibody was encoded by a PvuII-Styl fragment. The amino acid sequence of this segment is shown in the lower portion of the figure. This restriction fragment together with shorter synthetic fragments were inserted into pATH for expression as fusion proteins with

336-amino acid amino-terminal segments of anthranilate synthetase in $E$. coli. The amino acid sequences of P450IID6 encoded by these constructs are shown. These were analyzed by immunoblotting as shown in Fig. 2.

blunt-ended sites in the polylinker and CDNA were used or created by filling in $5^{\prime}$ or making flush $3^{\prime}$ overhangs at the selected site using Klenow fragment or T4-DNA polymerase (U.S. Biochemical Corp., Cleveland, $\mathrm{OH}$ ) respectively. The $5^{\prime}$ junction of the insert and polylinker region were sequenced to confirm orientation and reading frame.

Construction of a synthetic cDNA encoding the epitope. The following two oligonucleotides and their complements were synthesized and kindly provided by Dr. C. Glass, The Scripps Institute:

\section{5'-AATTCTGTTAACTGAGCACAGGATGACCTGGGATCCAGC}

\section{CCAGCCCCCCCGAGATCTGACTGAGGCCTTCCTGGCA-3'}

and

\section{5'-AGGCCTTCCTGGCAGAGATGGAGAAGGCCAAGGGGAAC}

TGA-3'.

These oligonucleotides were designed to encode almost all of the shortest immunopositive P450IID6/ $\beta$-galactosidase construct as two overlapping segments, and silent substitutions were incorporated (underlined nucleotides) to provide new restriction sites for additional deletion analysis. Equimolar amounts of each oligonucleotide were mixed in ligase buffer (Bethesda Research Laboratories), heated to $100^{\circ} \mathrm{C}$ for $5 \mathrm{~min}$, and then allowed to cool slowly to room temperature. The resulting double-stranded cDNA was inserted between the EcoRI and HindIII sites of pATH 1 (T. J. Koerner, Duke University). The sequence of the cloned construct was determined in pATH from the $3^{\prime}$ end using a pBR EcoRI primer (New England Biolabs, Beverly, MA) as well as following cloning of the insert into pBluescript SK-. Subsequent deletions were made in the pBluescript construct and confirmed by sequence analysis before being transferred to either pATH 1 or pATH 10. These pATH constructs were also verified by sequencing.

The resulting pATH constructs were transformed into SCS-1 cells (Stratagene, Inc.). The cells were cultured and processed for immunoblot analysis as described previously (10). Polyacrylamide gel electro- phoresis employed a discontinuous buffer system containing sodium dodecyl sulfate (SDS) (11). The concentration of monomer is stated in the figure legends. After electrophoresis the protein content of the gels was transferred electrophoretically to nitrocellulose (12). The nitrocellulose filters were probed with antibody as described previously (3), and bound antibodies were detected as described in the legends to figures.

Affinity purification of $L K M-1$ antibody. The peptide, DPAQPPRDC, and the control peptide IQEEAQCLVEER were synthesized and kindly provided by Dr. Richard Houghten of this institution. The first peptide contains an added carboxyl-terminal cysteine residue for immobilization of the peptide to Thiopropyl-Sepharose (Sigma Chemical Co., St. Louis, MO) as described by Parekh et al. (13). Purification of the antibody followed that outlined by the latter authors. Briefly, $100 \mu \mathrm{l}$ of antiserum was incubated with $50 \mu \mathrm{l}$ of packed resin for $4 \mathrm{~h}$ at room temperature with occasional mixing. The unbound material was recovered for later use. The resin was washed five times with $1 \mathrm{ml}$ of $0.01 \mathrm{M}$ $\mathrm{NaPi}, \mathrm{pH} 7.4$, containing $0.15 \mathrm{M} \mathrm{NaCl}$ (PBS). The antibody was eluted in $1 \mathrm{ml}$ of $0.1 \mathrm{M}$ citrate buffer containing $0.15 \mathrm{M} \mathrm{NaCl}$ at $\mathrm{pH} 3.0$ and after removal of the Sepharose, the solution was immediately neutralized by the addition of $150 \mu \mathrm{l}$ of $2 \mathrm{M}$ Tris buffer, $\mathrm{pH} \mathrm{8.0}$. The resulting affinity purified antibody was diluted in PBS or $3 \%$ bovine serum albumin (BSA) in PBS for use in enzyme-linked immunosorbent assays (ELISA) and immunoblotting respectively. The reactivity of the affinity-purified antibody with the fusion protein containing the segment of P450IID6 encoded by the PvuII-StyI fragment and native microsomal P450IID6 was confirmed by immunoblotting.

ELISA. The wells of a 96 -well polystyrene plate, Immulon II (NUNC, Copenhagen) were coated with $50 \mu$ l of human liver microsomes, $0.26 \mathrm{mg} / \mathrm{ml}$, in $50 \mathrm{mM} \mathrm{KP}$, $\mathrm{pH} 7.4$, containing $20 \%$ glycerol and $1 \mathrm{mM}$ EDTA. After overnight incubation at $4^{\circ} \mathrm{C}$, the excess microsomal suspension was removed and residual binding sites were blocked by incubation with $3 \%$ BSA in PBS. Serial dilutions ( $50 \mu \mathrm{l})$ of samples containing antibodies were incubated in the wells of the plate for $2 \mathrm{~h}$ at $37^{\circ} \mathrm{C}$. After extensive washes with PBS, a goat anti-human IgG alkaline phosphatase conjugate (Sigma Chemical Co.) was added to each 
well ( $50 \mu \mathrm{l}, 1: 700$ in PBS containing 3\% BSA) for $1 \mathrm{~h}$ at $37^{\circ} \mathrm{C}$. Substrate 104 (Sigma Chemical Co.) was used for color development according to the supplier's directions. Absorbance at $405 \mathrm{~nm}$ was determined. Antibodies to the $\mathrm{C} 100-3$ protein encoded by hepatitis $\mathrm{C}$ virus (HCV) were detected by an ELISA (14) from Ortho Diagnostics Raritan, NJ. Positive ELISA results were confirmed by the recombinant immunoblot assay (Chiron Corp., Emeryville, CA) test based on recombinant $\mathrm{HCV}$ proteins $\mathrm{C100-3}$ and 5-1-1, as well as a control for reactivity with the fusion partner, superoxide dismutase, used for expression of the recombinant $\mathrm{HCV}$ proteins. Serum antibodies to herpes simplex virus type 1 (HSV-1) were detected using an ELISA from Behringwerke, Marburg, Federal Republic of Germany.

Competitive radioimmunoassay (RIA). This assay has been described previously (7). Briefly, IgG was purified from the serum of a patient, R.H., used to identify the short epitope, DPAQPPRD. $75 \mu \mathrm{l}$ of the purified IgG $(0.2 \mathrm{mg}$ protein $/ \mathrm{ml}$ in PBS) was used to coat assay tubes (M 174, Dynatech, Deutschland GmbH, Plochingen, FRG) for 3 $h$ at $25^{\circ} \mathrm{C}$, the tubes were then washed with PBS, and remaining binding sites were blocked with $200 \mu \mathrm{l}$ of $0.1 \% \mathrm{BSA} / \mathrm{PBS}$ overnight at $4^{\circ} \mathrm{C}$. Human liver microsomes $(50 \mu \mathrm{l}$ at a concentration of $0.9 \mathrm{mg}$ protein/ $\mathrm{ml}$ ) were incubated in each tube for $3 \mathrm{~h}$ at $25^{\circ} \mathrm{C}$. Microsomes not bound by the antibody were removed by washing with PBS. The detection of competing autoantibodies in sera from other patients followed the blocking principle, i.e., $50 \mu$ l of test serum, diluted in PBS, were added to test tubes for $3 \mathrm{~h}$ at $25^{\circ} \mathrm{C}$ before the addition of $50 \mu \mathrm{l}$ of the purified IgG $(300,000 \mathrm{cpm})$, which was allowed to react for $3 \mathrm{~h}$ at $25^{\circ} \mathrm{C}$. Patient R.H. IgG was labeled with ${ }^{125}$ I by the chloramine-T method (15). After washing, the amount of labeled antibody which bound to the microsomes was determined. Each assay was done in duplicate, and the results represent the mean of two independent experiments. The method of analysis and additional details are provided in the legend to Fig. 3 and in the text. The interassay coefficient of variation ranged from $3.4 \%$ to $12.4 \%$ and the intra-assay coefficient of variation was between $2.0 \%$ and $15.6 \%$.

Infection of cultured cells with HSV-1. Lysates from BHK cells infected with HSV-1 and from noninfected BHK cells were kindly provided by Dr. M. Löhr of the University of Erlangen, FRG. Briefly, BHK cells at a density of $3 \times 10^{7}$ cells per flask were infected with HSV-1 at a multiplicity of infection of 1 . After overnight growth, the cells were harvested and washed in PBS. Washed cells were suspended in $100 \mu \mathrm{l}$ of PBS per flask containing detergent and sonicated three times for $30 \mathrm{~s}$ to produce the whole-cell lysate used for electrophoresis.

Sequence analysis. Computer assisted analysis of DNA and protein sequences were performed using the GCG Sequence Analysis Software
(Genetics Computer Group, Inc., Madison, WI) (16). The NBRF protein (September 1990 release) and Genbank/EMBL (December 1990 release) databases were queried using FASTA and TFASTA, respectively.

\section{Results}

Epitope mapping. In order to determine whether a single segment of the primary structure of human P450IID6 is recognized by LKM-1 antibodies, a panel of deletion mutants (Fig. 1), was constructed from the cDNA HLD8.2 (3) in pBluescript and subsequently expressed in Escherichia coli as fusion proteins with $\beta$-galactosidase. Earlier work had demonstrated that LKM-1 antibodies recognize the protein encoded by the HLD8.2 cDNA, which encodes all but the first 124 amino acid residues of P450IID6, when this cDNA is inserted into the pBS or pATH plasmids, and the protein is expressed in $E$. coli fused with a portion of either $\beta$-galactosidase or anthranilate synthetase, respectively (3). Colony lysates from the deletion panel in pBluescript were immobilized on nitrocellulose filters and probed with LKM-1 sera and ${ }^{125}$ I-Protein A using the colonyscreening procedure of Helfman et al. (8). These experiments indicated that the majority of LKM-1 sera bind to a fusion protein in lysates of $E$. coli, which contained a plasmid encoding the PvuII-Styl fragment corresponding to nucleotides 751850 of the HLD8.2 cDNA (3). A consistent pattern of reactivity was seen for overlapping constructs, and constructs encoding other segments of the protein were negative (Fig. 1).

In order to refine the localization of the epitope within the segment encoded by the PvulI-StyI fragment, two overlapping sets of complementary oligonucleotides were synthesized corresponding to this fragment. These contained additional restriction sites resulting from silent substitutions that facilitated the construction of further deletions from either end of the synthetic portion. The fragments produced in this manner (Fig. 1), as well as the PvuII-StyI fragment derived from the cDNA, were then inserted into pATH vectors for expression as fusion proteins with anthranilate synthetase. The resulting fusion proteins were examined in immunoblotting experiments employing LKM-1 antibodies and lysates of the transformed $E$. coli, as is shown for one serum in Fig. 2.

\section{SDS PAGE $\longrightarrow$}

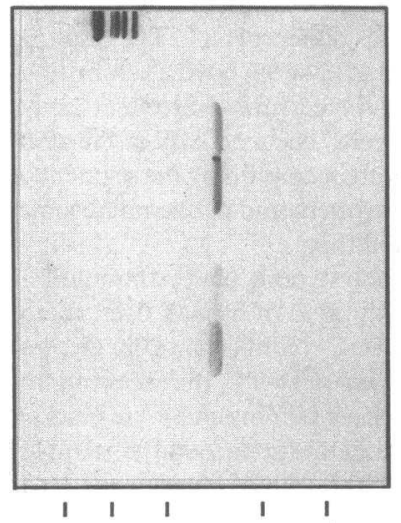

$92 \quad 66 \quad 45 \quad 3121 \quad k D$
Figure 2. Immunoblotting experiment to detect the binding of an LKM-1-positive serum with fusion proteins containing segments of P450IID6. Bacterial lysates were applied to the lanes of a 5-20\% gradient polyacrylamide gel containing SDS. The direction of migration is shown at the top. The portion of the sequence of IID6 expressed in the fusion protein is shown for each lane on the right. cDNA refers to the complete HLD8.2 insert (3). Some proteolytic degradation is evident for this construct. Ctrl designates the pATH vector containing no insert, whereas Ctrl-fs contains the longest synthetic fragment in the wrong reading frame. The bound antibody was detected using an immunoperoxidase stain. 
These experiments confirmed and extended the results seen earlier with the constructions in pBluescript. Of $26 \mathrm{LKM}-$ 1-positive sera, a total of 22 reacted with the fusion protein expressed from the construct harboring the PvuII-StyI fragment which encodes a 33-amino acid segment of P450IID6 (Table I). The smallest segment of this 33-amino acid portion of P450IID6, which yields an immunoreactive protein when fused with the 33-kD amino-terminal segment of anthranilate synthetase, encodes the amino acid sequence DPAQPPRD (Fig. 2). This small segment was recognized by 11 of the 26 sera (Table I). Moreover, it was present in the smallest positive segments that were recognized by the remaining LKM-1 sera (Table I). Five sera did not recognize the product of any deletion mutant smaller than that encoded by the PvuII-StyI fragment. This included two 23-mers encoding amino- and carboxyl-terminal segments of the 33-mer that overlapped for 11 amino acids. This region of overlap included the eight-amino acid core sequence recognized directly by 11 of the 26 antibodies. Although two patient sera recognized each 23-mer, they did not recognize a shorter construct encoding the 11-amino acid sequence shared by the two 23-mers. Four sera recognized a 15-mer that included the eight-amino acid "core" sequence DPAQPPRD, and these same sera did not react with the C8- mer and C15-mer (Fig. 1), which overlapped the positive 15mer but did not contain the core sequence. In many cases, the intensity of the signal diminished as the segment contained in the pATH construct became shorter, and thus, the differences in the size of the smallest segment which reacted with each antibody could reflect differences in titer that limit detection of their reactivity toward smaller fragments. We suspect that some portion of the core sequence, DPAQPPRD, is a necessary part of the epitope recognized by the majority of LKM-1 antibodies, but that it alone may not be sufficient for binding of all LKM-1-positive sera when expressed as a fusion protein and/ or when tested by immunoblotting. Also, the differences seen for these sera regarding their reactivity with segments smaller than the 33-amino acid segment may reflect the influence of the fusion protein on the conformation or accessibility of the epitope.

All of the sera, including the four sera that did not recognize the sequence encoded by the PvuII-Styl fragment expressed in pATH, inhibit the binding to the native protein of an antibody recognizing the core epitope as judged by a competitive radioimmunoassay. The results of this assay are summarized in Table I, and examples are shown in Fig. 3. In this assay, IgG was purified from the serum of the chronic active hepatitis patient,

Table I. Epitope Mapping for LKM-1 Autoantibodies

\begin{tabular}{|c|c|c|c|c|c|c|}
\hline Patient & Age & Sex & Smallest linear epitope & RIA & HCV & HSV-1 \\
\hline & $y r$ & & & & & \\
\hline K.B. & 64 & $\mathbf{M}$ & HLD8.2 cDNA & $<100$ & + & + \\
\hline S.A. & 62 & $\mathbf{F}$ & HLD8.2 cDNA & 100 & + & + \\
\hline P.B. & 24 & $\mathbf{M}$ & HLD8.2 cDNA & 500 & 0 & ND \\
\hline A.E. & 44 & $\mathbf{F}$ & HLD8.2 cDNA & 1,000 & + & + \\
\hline H.N. & 59 & $\mathbf{F}$ & LDELLTEHRMTWDPAQPPRDLTEAFLAEMEKAKGN & 100 & + & + \\
\hline B.J. & 66 & $\mathbf{M}$ & LDELLTEHRMTWDPAQPPRDLTEAFLAEMEKAKGN & 10 & + & + \\
\hline B.E. & 52 & $\mathbf{F}$ & LDELLTEHRMTWDPAQPPRDLTEAFLAEMEKAKGN & 100 & + & + \\
\hline T.D. & 41 & $\mathbf{F}$ & LDELLTEHRMTWDPAQPPRDLTEAFLAEMEKAKGN & 100 & + & + \\
\hline L.R. & 16 & $\mathbf{F}$ & LDELLTEHRMTWDPAQPPRDLTEAFLAEMEKAKGN & 4,000 & 0 & ND \\
\hline \multirow[t]{2}{*}{ S.V.* } & 22 & $\mathbf{F}$ & LDELLTEHRMTWDPAQPPRDLTE & 8,000 & 0 & $\mathrm{ND}^{\ddagger}$ \\
\hline & & & DPAQPPRDLTEAFLAEMEKAKGN & & & \\
\hline \multirow[t]{2}{*}{ M.M.* } & 23 & $\mathbf{F}$ & LDELLTEHRMTWDPAQPPRDLTE & 32,000 & 0 & ND \\
\hline & & & DPAQPPRDLTEAFLAEMEKAKGN & & & \\
\hline A.I. & 34 & $\mathbf{F}$ & DPAQPPRDLTEAFLA & 1,000 & $\mathbf{0}$ & + \\
\hline S.N. & 13 & $\mathbf{F}$ & DPAQPPRDLTEAFLA & 1,000 & 0 & 0 \\
\hline H.H. & 32 & $\mathbf{M}$ & DPAQPPRDLTEAFLA & 2,000 & + & + \\
\hline Bi.S. & 16 & $\mathbf{F}$ & DPAQPPRDLTEAFLA & 8,000 & 0 & 0 \\
\hline Ra.R. & 50 & $\mathbf{M}$ & DPAQPPRD & 500 & + & + \\
\hline L.P. & 30 & $\mathbf{F}$ & DPAQPPRD & 32,000 & 0 & 0 \\
\hline D.M. & 14 & $\mathbf{F}$ & DPAQPPRD & 64,000 & ND & ND \\
\hline U.M. & 15 & $\mathbf{M}$ & DPAQPPRD & 32,000 & 0 & + \\
\hline S.B. & 23 & $\mathbf{M}$ & DPAQPPRD & 4,000 & 0 & + \\
\hline K.S. & 13 & $\mathbf{F}$ & DPAQPPRD & 4,000 & 0 & + \\
\hline M.R. & 32 & $\mathbf{F}$ & DPAQPPRD & 16,000 & 0 & + \\
\hline R.H. & 24 & $\mathbf{F}$ & DPAQPPRD & 16,000 & 0 & + \\
\hline Re.R. & 61 & $\mathbf{M}$ & DPAQPPRD & 1,000 & + & + \\
\hline S.M. & 25 & $\mathbf{F}$ & DPAQPPRD & 8,000 & ND & ND \\
\hline Be.S. & 24 & $\mathbf{F}$ & DPAQPPRD & 8,000 & + & + \\
\hline
\end{tabular}

Smallest linear epitope: sequence of the smallest cDNA construct in pATH 11 recognized as fusion protein by the patients serum on immunoblots. Abbreviations: F, female; HCV, antibodies against hepatitis C virus proteins; M, male; ND; not determined; RIA, reciprocal titer for LKM-1 antibodies in a competitive radioimmunoassay. ${ }^{*}$ Recognize two overlapping 23 amino acid segments. ${ }^{\ddagger}$ Negative by immunoblotting (Fig. 5 ). 


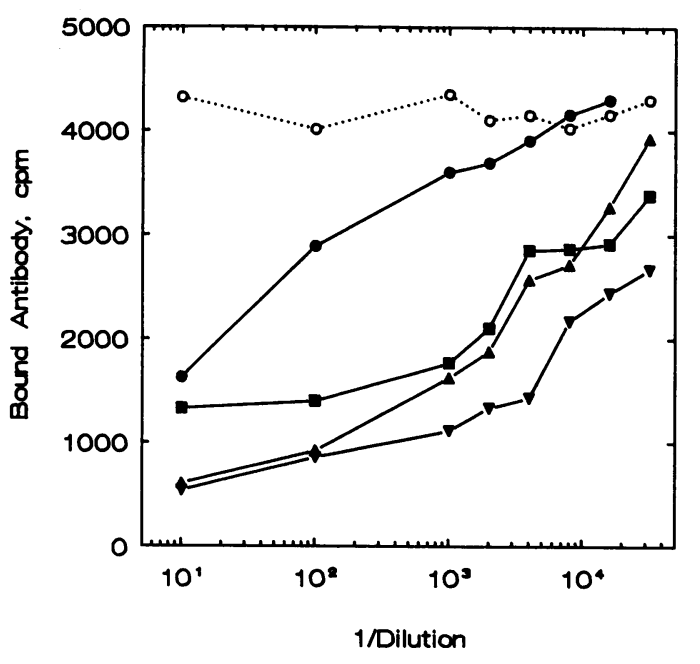

Figure 3. Competition for binding to human liver microsomes between ${ }^{125}$ I-LKM-1 IgG, from patient R.H., and other LKM-1 sera. The titers producing $40 \%$ inhibition for each serum are listed in Table I. The examples shown exhibited differences in the smallest segment of P450IID6 which each recognized: The labeled antibody recognized the 8-mer or larger; serum Bi.S. ( $($ ) recognized the 15-mer or larger; serum M.M. ( $\nabla)$ recognized the two overlapping 23-mers or larger; serum L.R. ( $\Delta$ ) recognized the PvulI-StyI segment or larger; whereas serum K.B. (•) recognizes the HLD8.2 cDNA but did not recognize the shorter pATH constructs as judged by immunoblotting. No inhibition by normal human serum was seen (O).

R.H., (Table I) and labeled with ${ }^{125} \mathrm{I}$. This serum recognizes a single protein corresponding in size to P450IID6 in human liver microsomes by immunoblotting as well as the shortest, eight-amino acid segment of P450IID6 expressed from pATH. The capacity of dilutions of the other 25 LKM-1 sera to inhibit the binding of the ${ }^{125}$ I-antibody to human liver microsomes was then determined. The highest dilution at which $40 \%$ or greater inhibition was observed in experiments such as those illustrated in Fig. 3 is reported in Table I. Although four sera do not react with the short linear segments of P450IID6 expressed from pATH constructs in $E$. coli as judged by immunoblotting, they clearly inhibit the binding of the reference antibody to microsomal P450IID6 (Table I and the example shown in Fig. 3 ). The concentrations required were, however, at the high end of the range seen for these sera (Table I). In contrast, sera that react with the shortest segment generally inhibit the binding of the reference serum at the lowest concentrations.

Antibodies to HCV proteins. As high as 78\% of LKM-1-positive sera from patients with idiopathic autoimmune chronic active hepatitis have been reported to exhibit antibodies to HCV protein $\mathrm{C100-3}$ as judged by commercial ELISA procedures (17-20). 11 of 24 LKM-1 sera tested from our panel were shown to be positive for anti-HCV C100-3 using both the Ortho Diagnostics ELISA and the Chiron Corp. RIBA tests (Table I). All but two of the sera were also positive for the HCV 5-1-1 protein, and all antisera were negative against superoxide dismutase which is the fusion partner for expression of the recombinant $\mathrm{HCV}$ proteins. As shown in Fig. 4, LKM-1-positive patients whose sera react with the HCV C100-3 protein used in these tests (14) generally exhibit a higher age and a lower LKM-1 antibody titer, as judged by the competitive RIA, suggesting two distinct populations of patients. In addition, a

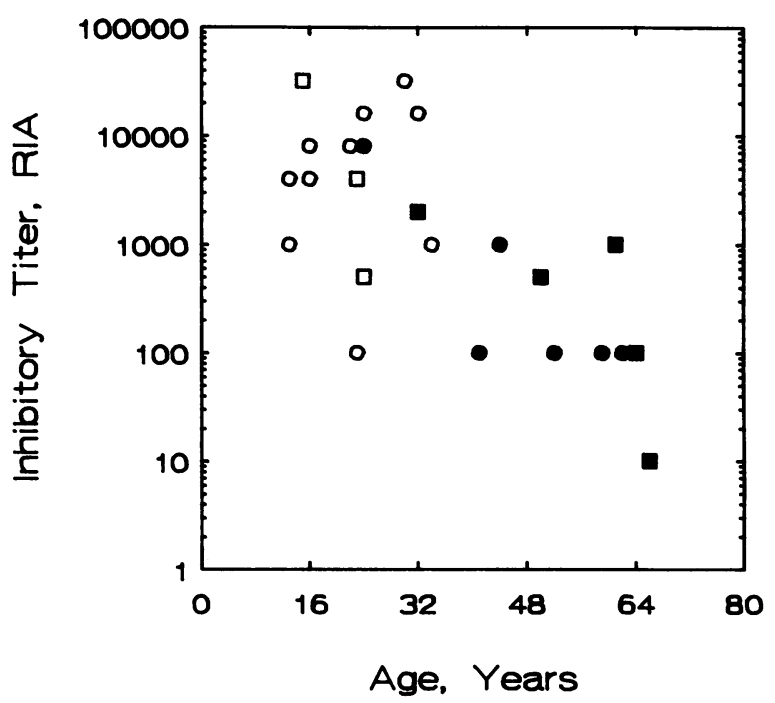

Figure 4. Distribution of anti-HCV-positive (solid symbols) and anti-HCV-negative (open symbols), among LKM-1-positive sera according to age of the patient and inhibitory titer of the antiserum in the competitive RIA against an LKM-1 serum recognizing the short epitope. Males are depicted by square symbols and females are represented by circular symbols. Data are taken from Table I.

lower female predominance is seen for anti-HCV positive sera than is seen for the group that did not exhibit antibodies to HCV proteins, as summarized in Table II. Both the HCV antibody-positive and -negative groups exhibit antibodies recognizing the 8 amino acid segment of P450IID6 as well as sera that did not react with the 33-amino acid or shorter epitopes expressed as fusion proteins in this study.

In order to test whether the LKM-1 autoantibody recognizes the $\mathrm{C100-3}$ protein of $\mathrm{HCV}$ used in the Ortho Diagnostics ELISA, the antibody was affinity-purified from an anti-HCVpositive serum by adsorption to the expressed recombinant HLD 8.2 cDNA and subsequent elution as described earlier (3). The purified antibody did not react with the HCV-encoded C100-3 protein in the Ortho Diagnostics ELISA or Chiron Corp. RIBA.

Sequence-relatedness of the epitope to other proteins. A search of the Genbank, EMBL, and NBRF databases revealed several sequences similar to that of the core epitope. With the exception of other P450s of the IID subfamily, the most striking match occurs with the immediate-early protein IE175 of HSV-1. Identity is seen for the sequence, PAQPPR, which occurs in both the IE175 (also denoted ICP4) protein of HSV-1 (21) and the core epitope. IE175 is expressed at relatively low concentrations during early stages of infection to regulate subsequent gene expression (22). Antibodies have been observed to arise to this protein, and for neonatal patients, the presence of these antibodies has been associated with a poor clinical outcome (23).

A screen of patient sera revealed that 17 of the 20 LKM-1-positive sera tested were also positive for antibodies to HSV-1 (Table I). When several of these were examined by immunoblotting they were found to react strongly with an extensive array of proteins in lysates from BHK cells infected with HSV-1, whereas this reactivity was not seen for lysates from the uninfected BHK cells. In the example shown in Fig. 5, the 
Table II. LKM-1-positive Patients with and without Anti-HCV Antibody Recognize the Core Epitope

\begin{tabular}{lcc}
\hline & HCV + & HCV- \\
\hline Age $(\mathrm{yr}$, mean \pm SD) & $51 \pm 13$ & $21 \pm 7^{*}$ \\
Ratio of sexes (F/M) & $6: 5$ & $10: 3$ \\
Total & 11 & 13 \\
LDELLTEHRMTWDPAQPPRDLTEAFLAEMEKAKGN & 8 & 12 \\
DPAQPPRD & 3 & 6 \\
LKM-1-RIA $\left(\log _{10}\right.$, titer) & $2.5 \pm 0.8$ & $3.6 \pm 0.7^{*}$ \\
\end{tabular}

${ }^{*} P<0.05, t$ test.

serum from a LKM-1 positive patient, K.S., is also positive for HSV-1 antibodies as demonstrated by reactivity with a large number of proteins expressed in the cells infected with HSV-1, whereas these proteins are not detected in uninfected cells or by serum from the patient's identical twin (Fig. 5, K.S. twin) who does not have autoimmune hepatitis or exhibit LKM-1 autoantibodies (24). On the other hand, four LKM-1-positive sera were negative not only when tested using the commercial assay but also when examined by immunoblotting-Table I and example shown in Fig. 5 (S.V.). Thus, most but not all LKM-1-positive sera also exhibit extensive reactivity toward proteins associated with $\mathrm{HSV}-1$ infection.

In order to determine whether the LKM-1 autoantibody reactive with the small epitope was one of the antibodies that recognize proteins associated with HSV-1 infection, we immunoaffinity-purified the antibody using a peptide linked to sepharose. A peptide was synthesized corresponding to the smallest positive fragment, DPAQPPRD, with an additional carboxylterminal cysteine which was used to immobilize the peptide to thiolpropyl sepharose (13). An LKM-1-positive serum was then incubated with the peptide-Sepharose, and the sequestered LKM-1 antibody was subsequently eluted. As shown in Fig. 6, the antibody eluted from the peptide-Sepharose reacts strongly with both a $50-\mathrm{kD}$ protein in human liver microsomes as well as with the roughly $40 \mathrm{kD}$ fusion protein containing the sequence DPAQPPRD. In contrast, incubation of LKM-1-positive sera with a peptide-Sepharose generated with a different peptide, IQEEAQCLVEER, did not lead to isolation of an antibody which detects these proteins in immunoblotting experiments (data not shown).

As shown in Fig. 6, the affinity-purified antibody recognizes a high molecular weight protein expressed after infection

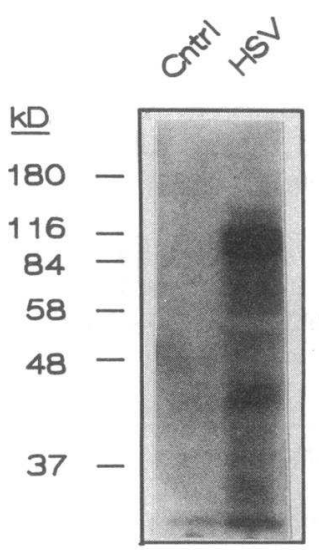

LKM K.S.

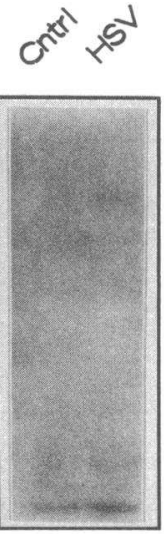

K.S. TWIN
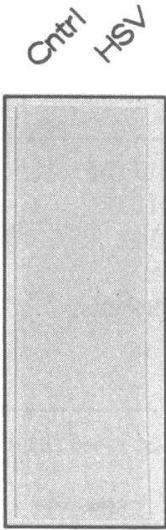

LKM S.V.
Figure 5. Reaction of human sera with lysates prepared from BHK cells after infection with HSV-1 or without infection (Cntrl). The SDS-solubilized lysates were applied to a $7.5 \%$ polyacrylamide gel containing SDS. After electrophoresis, the proteins were electrophoretically transferred to nitrocellulose which was cut into strips for incubation with individual sera. Bound antibodies were detected by ${ }^{125} \mathrm{I}$-protein A (ICN Biomedicals, Inc., > $30 \mathrm{Ci} / \mathrm{g}$ ) and autoradiography. LKM-1-positive serum (LKM K.S.), serum from the patient's (K.S.) twin sibling who is unaffected by the disease (K.S. TWIN), and LKM-1-positive serum (LKM S.V.) for which no reactivity is seen are shown in the three panels.
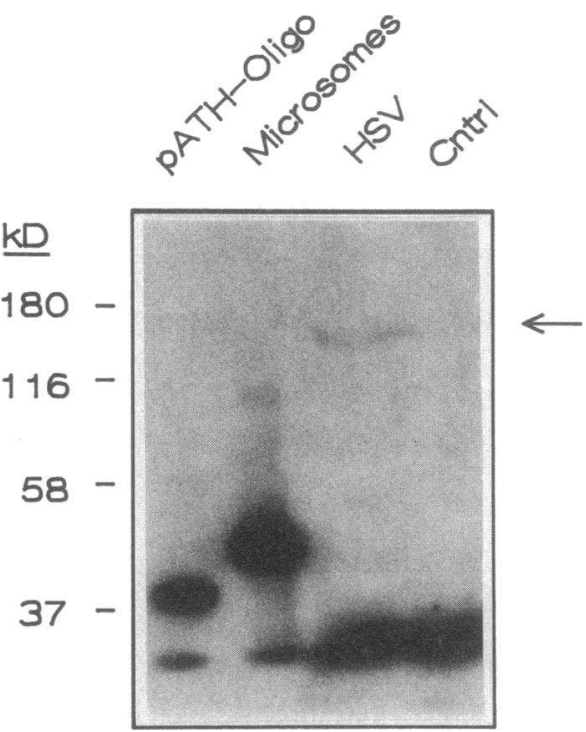

Figure 6. Detection of a high molecular weight protein associated with HSV-1 infection of BHK cells by an affinity-purified LKM-1 antibody. The lanes contain the following: $p A T H$-oligo, lysate from $E$. coli harboring the pATH vector containing an insert coding for the 8-mer, DPAQPPRD; Microsomes, $10 \mu \mathrm{g}$ of human liver microsomes; HSV, $250 \mu$ l of lysate from BHK cells infected with HSV-1; and Cntrl, noninfected BHK cells. The antibody was purified using DPAQPPRDC-Sepharose, and the bound antibody was detected by ${ }^{125}$ I-protein A. 
of BHK cells with HSV-1, whereas a protein is not detected by the antibody in lysates from cells which were not infected. The intensity of the band is weak and a 10 times greater amount of BHK cell lysate was loaded in this experiment than that shown in Fig. 5. This analysis does not indicate that the protein recognized is IE175, however, the estimated size of the protein detected by the affinity-purified antibody, $150 \pm 20 \mathrm{kD}$, is consistent with this possibility. This experiment also demonstrates the ability of the peptide-Sepharose to purify the LKM-1 antibody effectively from antibodies in the serum that recognize other proteins expressed in BHK cells infected with HSV-1.

An ELISA assay was used to determine the extent to which three-repeated adsorptions with the peptide-Sepharose reduced the titer of the autoantibody against human liver microsomes. As shown in Fig. 7, the titer was reduced by $\sim 10$-fold whereas it was unaffected by adsorption with the control peptide linked to Sepharose, indicating that this reactivity represents a major component of the LKM-1 autoantibodies present. Immunoblotting demonstrated that the residual LKM-1 autoantibodies exhibit reactivity toward the smallest segment of P450IID6 expressed as a fusion protein, suggesting that incomplete adsorption contributed to the remaining reactivity (data not shown).

\section{Discussion}

The majority, 22 of 26, of LKM-1-positive sera from patients with autoimmune chronic active hepatitis tested in this study react with a 33-amino acid segment of P450IID6 when it is expressed as a fusion protein. Most of these sera react with smaller segments that include the sequence DPAQPPRD which is recognized directly by 11 of the 22 sera that recognize

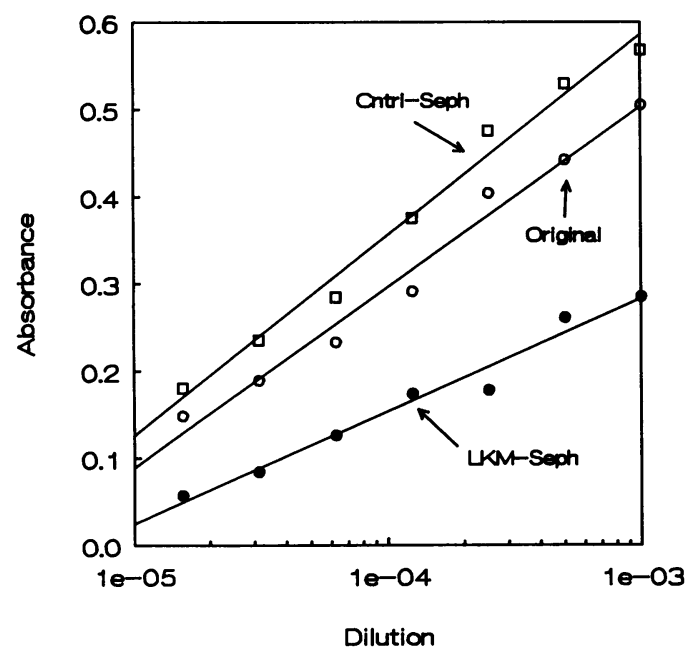

Figure 7. Determination of LKM-1 autoantibody depletion by peptide-Sepharoses. LKM-1-positive serum (Original, o) was incubated with either the DPAQPPRDC-Sepharose (LKM-Seph, $\bullet$ ) or an unrelated peptide Sepharose (Cntrl-Seph, $\square$ ), as described in Methods. The serum was recovered from the incubation and combined with the first two washes. The volume was adjusted to yield a 1:100 dilution relative to the original serum sample. Duplicate serial dilutions were then used in an ELISA assay which employed human liver microsomes as the bound antigen. The amount of antibody bound to the plate was determined using an alkaline-phosphatase conjugate to goat anti-human IgG and monitoring color development at $405 \mathrm{~nm}$ using $p$-nitrophenyl phosphate as the substrate. the 33-amino acid segment. Although the differences seen between sera in their ability to react with segments shorter than the 33-amino acid sequence is suggestive of differences in the epitope recognized by each sera, the conformation of the core epitope may have been altered by the deletion of flanking sequences and the subsequent replacement of these segments with elements of the fusion protein. This might diminish the binding of the short segment with LKM-1 antibodies, and the binding of low titer sera with the short segment might not be detectable for this reason.

A comparison of the sequences of P450IID6 with class IID sequences from other species which are known to react with LKM-1 antibodies is consistent with this assessment. Gueguen et al. (25) screened a $\lambda$ GT 11 , rat liver cDNA library using three LKM-1-positive sera from children. They characterized four immunopositive, partial cDNAs corresponding to rat P450IID1 and P450IID2. These clones exhibited a 350-bp region of overlap leading these authors to speculate that the region of overlap encoded the epitope recognized by the three antisera. From the restriction maps presented by these authors (25), this region of overlap appears to contain rat sequences which align with the epitope identified in our studies. As is shown in Fig. 8, the sequence of the core epitope is conserved in both rat P450IID1 and P450IID2, whereas flanking sequences are seen to diverge. In addition, we have sequenced a partial cDNA which was identified and isolated from a rabbit liver cDNA library by hybridization with the HLD 8.2 cDNA. This fragment encodes amino acids corresponding to 158-427 of human P450IID6, and the fusion protein expressed from this plasmid is also recognized by LKM-1 antibodies (Johnson, E. F., and K. J. Griffin, unpublished observation). The amino acid sequence predicted from the nucleotide sequence is also shown in Fig. 8 for the region corresponding to the epitope.

Specific details regarding the location of the epitope in the structure of P450IID6 have not been determined, although a correspondence with the structure of P450CI, a distantly re-

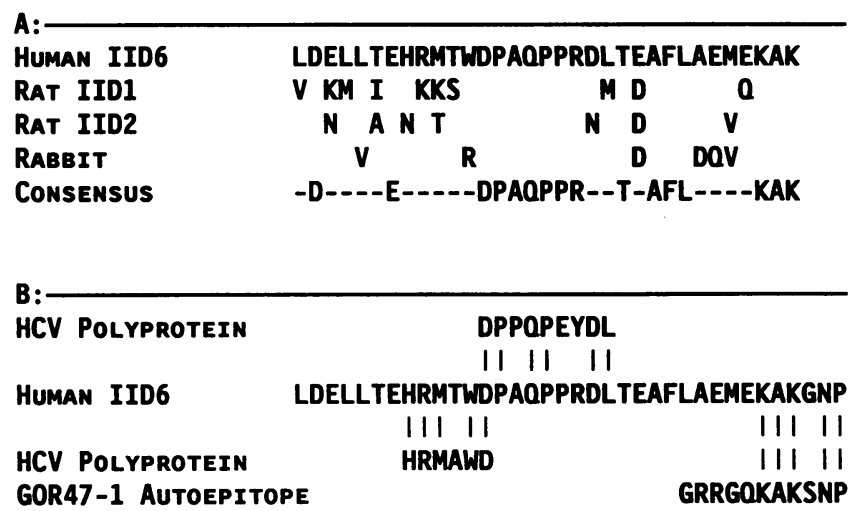

Figure 8. (A) Amino acid sequences of class IID P450s that bind LKM-1 antibodies. The sequence of human P450IID6 corresponds to the segment encoded by the PvulI-Styl fragment. This sequence was recognized by 22 of the 26 LKM-1 sera tested. Only differences are shown where they occur for the corresponding segments of rat IID1 and IID2 $(25,27)$ and for an immunopositive rabbit cDNA characterized in our laboratory. A consensus sequence is shown on the bottom line. $(B)$ The sequence, GOR47-1, recognized by sera from $87 \%$ of nonA, nonB-hepatitis patients tested $(28)$ and two segments of the putative HCV polyprotein (29) are aligned with a portion of the sequence of P450IID6 harboring the LKM-1 epitope. 
lated form of $\mathrm{P} 450$, has been predicted by several investigators (30-32). Based on these models, the core epitope recognized by LKM-1 antibodies would occur between helices corresponding to $\mathrm{G}$ and $\mathrm{H}$ of $\mathrm{P450CI}$ which is a protruding loop on the surface of the P450CI enzyme (33).

The genesis of autoantibodies to such a highly conserved region of the protein is unknown. Although host factors such as HLA restriction and the polymorphism of P450IID6 genes could contribute to an idiotypic autoimmune response that leads to LKM-1 autoantibodies, environmental factors are also thought to contribute to this process. For instance, one of the patients under study in this report has an identical twin. The twins exhibit identical HLA types, and each is an obligate heterozygote for a wild type and a defective allele of P450IID6. Yet only one of the twins is affected by this autoimmune disorder and exhibits LKM-1 autoantibodies (24), suggesting that some environmental factor contributes to the development of disease.

Viruses have been implicated as causative agents in autoimmune disorders $(34,35)$, and we have shown that the epitope defined here contains a six-amino acid sequence found in the IE175 protein of HSV-1 (21). Many, but not all, LKM-1-positive patient sera including many of those that react with the short linear sequence exhibit immunoreactivity toward a large number of proteins associated with HSV-1 infection of BHK cells. This group includes the patient who is the only one of a twin pair affected by autoimmune hepatitis. The other twin does not exhibit reactivity with proteins associated with HSV-1 infection of BHK cells (Fig. 5). A peptide corresponding to the short linear epitope was used for the affinity purification of LKM-1 antibodies from a patient's serum. In contrast to the large number of proteins that react with the complete serum, the purified antibody reacts with only a single protein associated with HSV-1 infection of BHK cells. This does not confirm that LKM-1 antibodies react with IE175, but it does illustrate the potential for cross recognition of proteins associated with viral infection.

While such "mimicry" has been suggested to lead to autoimmunity $(34,35)$, it seems unlikely that all LKM-1 antibodies arise directly from an immune response to IE175. First, 4 of 20 LKM-1 sera do not exhibit evidence for other antibodies directed toward HSV-1 proteins as judged by a commercial assay, and one of these sera reacts with the smallest, eight-amino acid, core epitope. Secondly, the differences seen between LKM-1 antibodies suggest that although many recognize this short epitope they are generally more reactive toward larger segments of P450IID6 which do not appear to mimic IE175.

$\mathrm{HCV}$ has been implicated as the major causative agent of NonA, NonB-transfusion related hepatitis $(14,36)$. Antibodies to $\mathrm{HCV}$ proteins have been reported to occur frequently (up to $78 \%$ ) in LKM-1-positive autoimmune hepatitis patients (1720), whereas the incidence of anti-HCV in other groups of autoimmune liver diseases is less profound (Manns, Gerken, Hess, and Meyer zum Büschenfelde, unpublished data). In our study, anti-HCV-positive patients were found to have, on average, a higher age, lower LKM-1 inhibitory titers in the RIA and a lower predominance of females as compared with the anti-HCV-negative patients. This suggests that LKM-1 antibodies may be associated with at least two distinct populations that reflect different origins for this disorder.

$\mathrm{HCV}$ has been associated with an autoimmune response to an endogenous antigen of unknown function. Mishiro et al.
(28) identified autoantibodies in the sera of $87 \%$ of the nonA-, nonB-hepatitis patients tested that recognize an endogenous protein encoded by a cDNA designated, GOR47-1. 67\% of these patients were positive for anti-HCV (C100-3), and HCVrelated mRNAs were detected in additional patients using a polymerase chain reaction assay. This raises the possibility that HCV contributes to the autoimmune response to P450IID6. Although LKM-1 antibodies affinity-purified from the fusion protein derived from the HLD8.2 cDNA do not cross-react with the HCV C100-3 protein, the segment of P450IID6 harboring the epitope recognized by LKM-1 antibodies exhibits partial sequence identity with the other segments of the polyprotein encoded by HCV as well as the GOR47-1 autoantigen. Two segments of the polyprotein (29) that are not present in the $\mathrm{C100-3}$ or 5-1-1 protein (37) exhibit partial sequence identity with P450IID6 (Fig. 8). One significantly overlaps the core epitope whereas the other is found in the region that flanks the core epitope in the 33-amino acid immunoreactive segment. Moreover, five of six amino acids in a segment of the GOR47-1 epitope occur adjacent to the epitope defined in this study for LKM-1 antibodies in the sequence of P450IID6 (Fig. 8). These similarities suggest a potential for immune cross-recognition between P450IID6 and the HCV polyprotein as well as the GOR47-1 protein which could be related to the occurrence of LKM-1 autoantibodies in patients with autoimmune hepatitis that are seropositive for anti-HCV.

Future studies will have to evaluate the role of either HSV-1 or HCV in the etiology of autoimmune liver disease. In addition, work is in progress to define T cell epitopes for P450IID6, and the constructions made in this study will be useful for this purpose. It will be interesting to determine whether the amino acid segments that flank the core epitope and display identity with HCV and GOR47-1 represent T cell epitopes.

\section{Acknowledgments}

HSV-1-infected BHK cells and control BHK cells were kindly provided by Dr. M. Löhr, Molecular Biology Laboratory, Department of Medicine I, University of Erlangen, FRG. The authors are grateful for the discussions and the support by E. M. Tan, The Scripps Research Institute, and K. H. Meyer zum Büschfelde, the University of Mainz, FRG. They also acknowledge the excellent technical assistance of Ms. U. Dang. The anti-HSV-1 antibody assay was kindly performed by Prof. D. Falke, Institute für Medizinische Mikrobiologie, Mainz, FRG. Sera from the family with identical twins (reference 24) were kindly provided from Dr. S. Koletzko, University of Düsseldorf, FRG. Oligonucleotides and synthetic peptides were synthesized by Dr. C. Glass and Dr. R. Houghten, respectively, at The Scripps Research Institute.

This study was supported by grant SFB 311 ,A1, from the Deutsche Forschungsgemeinschaft (Dr. Manns), NATO Collaboration Research Grant No. 5-2-05/RG-891003 (Dr. Manns), and U. S. Public Health Service grant GM-31001 (Dr. Johnson). Facilities for computer-assisted analysis and the synthesis of oligonucleotides are supported in part by General Clinical Research Center grant M01 RR-00833 and by the Sam and Rose Stein Charitable Trust, respectively.

\section{References}

1. Manns, M. 1989. Autoantibodies and antigens in liver diseases-updated. J. Hepatol. 9:272-280.

2. Nebert, D. W., D. R. Nelson, M. J. Coon, R. W. Estabrook, R. Feyereisen, Y. Fujii-Kuriyama, F. J. Gonzalez, F. P. Guengerich, I. C. Gunsalus, E. F. Johnson, et al. 1991. The P450 superfamily: update on new sequences, gene mapping. and recommended nomenclature. DNA Cell Biol. 10:1-14. 
3. Manns, M. P., E. F. Johnson, K. J. Griffin, E. M. Tan, and K. F. Sullivan. 1989. Major antigen of liver kidney microsomal autoantibodies in idiopathic autoimmune hepatitis is cytochrome P450db1. J. Clin. Invest. 83:1066-1072.

4. Gueguen, M., A. M. Yamamoto, O. Bernard, and F. Alvarez. 1989. Antiliver kidney microsome antibody type 1 recognizes human cytochrome $P 450 \mathrm{dbl}$. Biochem. Biophys. Res. Commun. 159:542-547.

5. Zanger, U. M., H.-P. Hauri, J. Loeper, J. -C. Homberg, and U. A. Meyer. 1988. Antibodies against human cytochrome $\mathrm{P}-450 \mathrm{dbl}$ in autoimmune hepatitis type II. Proc. Natl. Acad. Sci. USA. 85:8256-8260.

6. Meyer, U. A., R. C. Skoda, and U. M. Zanger. 1990. The genetic polymorphism of debrisoquine/sparteine metabolism-molecular mechanisms. Pharmacol. Ther. 46:297-308.

7. Manns, M., K. -H. Meyer zum Büschenfelde, J. Slusarczyk, and H. P. Dienes. 1984. Detection of liver-kidney microsomal autoantibodies by radioimmunoassay and their relation to anti-mitochondrial antibodies in inflammatory liver diseases. Clin. Exp. Immunol. 57:600-608.

8. Helfman, D. M., J. R. Feramisco, J. C. Fiddes, G. P. Thomas, and S. H Hughes. 1983. Identification of clones that encode chicken tropomyosin by direct immunological screening of a cDNA expression library. Proc. Natl. Acad. Sci. USA. 80:31-35.

9. Gonzalez, F. J., R. C. Skoda, S. Kimura, M. Umeno, U. M. Zanger, D. W. Nebert, H. V. Gelboin, J. P. Hardwick, and U. A. Meyer. 1988. Characterization of the common genetic defect in humans deficient in debrisoquine metabolism. Nature (Lond.). 331:442-446.

10. Earnshaw, W. C., K. F. Sullivan, P. S. Machlin, C. A. Cooke, D. A. Kaiser, T. D. Pollard, N. F. Rothfield, and D. W. Cleveland. 1987. Molecular cloning of cDNA for CENP-B, the major human centromere autoantigen. J. Cell Biol. 104:817-829.

11. Laemmli, U. K. 1970. Cleavage of structural proteins during the assembly of the head of bacteriophage T4. Nature (Lond.). 227:680-685.

12. Towbin, H., S. Theophil, and J. Gordon. 1979. Electrophoretic transfer of proteins from polyacrylamide gels to nitrocellulose sheets: procedure and some applications. Proc. Natl. Acad. Sci. USA. 76:4350-4354.

13. Parekh, B. S., P. W. Schwimbeck, and M. J. Buchmeir. 1989. High efficiency immunoaffinity purification of anti-peptide antibodies on thiopropyl sepharose immunoadsorbants. Peptide Res. 2:249-252.

14. Kuo, G., Q. -L. Choo, H. J. Alter, G. L. Gitnick, A. G. Redeker, R. H. Purcell, T. Miyamura, J. L. Dienstag, M. J. Alter, C. E. Stevens, et al. 1989. An assay for circulating antibodies to a major etiologic virus of human non-A, non-B hepatitis. Science (Wash. DC). 244:362-364.

15. Hunter, W. M., and F. C. Greenwood. 1962. Preparation of iodine-131 labelled human growth hormone of high specific activity. Nature (Lond.). 194:495-496.

16. Devereux, J., P. Haeberli, and O. Smithies. 1984. A comprehensive set of sequence analysis programs for the VAX. Nucleic Acids Res. 12:387-395.

17. Lenzi, M., G. Ballardini, M. Fusconi, F. Cassani, L. Selleri, U. Volta, D. Zauli, and F. B. Bianchi. 1990. Type 2 autoimmune hepatitis and hepatitis $C$ virus infection. Lancet. 335:258-259.

18. McFarlane, I. G., H. M. Smith, P. J. Johnson, G. P. Bray, D. Vergani, and R. Williams. 1990. Hepatitis C virus antibodies in chronic active hepatitis: Pathogenetic factor or false-positive result. Lancet. 335:754-757.

19. Vento, S., G. Di Perri, R. Luzzati, T. Garofano, E. Concia, and D. Bassetti. 1990. Type 2 autoimmune hepatitis and hepatitis $C$ virus infection. Lancet. 335:921-922.

20. Fusconi, M., M. Lenzi, G. Ballardini, R. Miniero, F. Cassani, D. Zauli, and F. B. Bianchi. 1990. Anti-HCV testing in autoimmune hepatitis and primary biliary cirrhosis. Lancet. 336:823.
21. McGeoch, D. J., A. Dolan, S. Donald, and D. H. K. Brauer. 1986. Complete DNA sequence of the short repeat region in the genome of herpes simplex virus type I. Nucleic Acids Res. 14:1727-1745.

22. DiDonato, J. A., and M. T. Muller. 1989. DNA binding and gene regulation by the herpes simplex virus type 1 protein ICP4 and involvement of the TATA element. J. Virol. 63:3737-3747.

23. Kahlon, J., and R. J. Whitley. 1988. Antibody response of the newborn after herpes simplex virus infection. J. Infect. Dis. 158:925-933.

24. Manns, M., S. Koletzko, H. Lohr, F. Borchard, C. Rittner, K. -H. Meyer zum Buschenfelde, and M. Eichelbaum. 1990. Discordant manifestation of LKM-1 antibody positive autoimmune hepatitis in identical twins. Hepatology (Baltimore). 12:840.

25. Gueguen, M., M. Meunier-Rotival, O. Bernard, and F. Alvarez. 1988. Anti-liver kidney microsome antibody recognizes a cytochrome P450 from the IID subfamily. J. Exp. Med. 168:801-806.

26. Gonzalez, F. J., T. Matsunaga, K. Nagata, U. A. Meyer, D. W. Nebert, J. Pastewka, C. A. Kozak, J. Gillette, H. V. Gelboin, and J. P. Hardwick. 1987. Debrisoquine 4-hydroxylase: Characterization of a new P450 gene subfamily, regulation, chromosomal mapping and molecular analysis of the DA rat polymorphism. DNA (NY). 6:149-161.

27. Ishida, N., Y. Tawaragi, C. Inuzuka, O. Sugita, I. Kubota, H. Nakazato, T. Noguchi, and S. Sassa. 1988. Four species of cDNAs for cytochrome P450 isozymes immunorelated to P450c-M/F encode for members of P450IID subfamily, increasing the number of members within the subfamily. Biochem. Biophys. Res. Commun. 156:681-688.

28. Mishiro, S., Y. Hoshi, K. Takeda, A. Yoshikawa, T. Gotanda, K. Takahashi, Y. Akahane, H. Yoshizawa, H. Okamoto, F. Tsuda, et al. 1990. Non-A non-B hepatitis specific antibodies directed at host-derived epitope: Implication for an autoimmune process. Lancet. 336:1400-1403.

29. Kato, N., M. Hijikata, Y. Ootsuyama, M. Nakagawa, S. Ohkoshi, T. Sugimura, and K. Shimotohno. 1990. Molecular cloning of the human hepatitis C virus genome from Japanese patients with non-A, non-B hepatitis. Proc. Natl. Acad. Sci. USA. 87:9524-9528.

30. Nelson, D. R., and H. W. Strobel. 1989. Secondary structure prediction of 52 membrane-bound cytochromes P450 shows a strong structural similarity to P450 ${ }_{\text {cam }}$. Biochemistry. 28:656-660.

31. Edwards, R. J., B. P. Murray, A. R. Boobis, and D. S. Davies. 1989. Identification and location of $\alpha$-helices in mammalian cytochrome P450. Bio chemistry. 28:3762-3770.

32. Gotoh, O., and Y. Fujii-Kuriyama. 1989. Evolution, structure, and gene regulation of cytochrome P-450. In Frontiers in Biotransformation. Basis and Mechanisms of Regulation of Cytochrome P-450. K. Ruckpaul and H. Rein, editors. Taylor \& Francis, New York. 195-243.

33. Poulos, T. L., B. C. Finzel, and A. J. Howard. 1987. High-resolution crystal structure of cytochrome P450cam. J. Mol. Biol. 195:687-700.

34. Oldstone, M. B. A. 1987. Molecular mimicry and autoimmune disease. Cell. 50:819-820.

35. Schattner, A., and B. Rager-Zisman. 1990. Virus-induced autoimmunity. Rev. Infect. Dis. 12:204-222.

36. Weiner, A. J., G. Kuo, D. W. Bradley, F. Bonino, G. Saracco, C. Lee, J. Rosenblatt, Q. -L. Choo, and M. Houghton. 1990. Detection of hepatitis C viral sequences in non-A, non-B hepatitis. Lancet. 335:1-3.

37. Houghton, M., Q. - L. Choo, and G. Kuo. 1989. Nanbv diagnostics and vaccines. European Patent Application 88310922.5 and Publication No. 0318 216 Al, European Patent Office. 